\title{
Study on the Diffusion Mechanism of Indoor Environmental Pollutants
}

\author{
Zhange Peng ${ }^{1,}$, , Lingjie Chen
}

\author{
${ }^{1}$ College of urban Construction and Safety Engineering, Shanghai Institute of Technology, \\ Shanghai 201418, P.R.China
}

apengsit@126.com

\begin{abstract}
Keywords:pollutant dispersion;air distribution;numerical simulation;diffusion mechanism
Abstract:The vortex and backflow phenomenon caused by many unreasonable designs in the indoor air environment make the velocity, pressure and temperature field distributed unevenly. These results bring out the indoor volatile pollutants local concentration is high. With numerical simulation analysis to pollutant flow field, the benzene concentration, temperature, relative humidity and the change of airflow velocity on the height direction were studied. The influence affected by indoor air change, temperature, relative humidity to pollutant diffusing dilution was discussed. The result analyzed indoor environment pollutant artificial guide flow diffusion mechanism can be a reference for solving these pollution problems. The results indicate that the benzene can be removed from the room effectively through increasing the indoor temperature, relative humidity and adding replacement ventilation quantity.
\end{abstract}

\section{Introduction}

With the development of society and the improvement of living standards, more and more artificial composite materials are used for indoor decoration [1-3]. The accompanying problem is that the release of volatile organic compounds (VOCs) from various materials is more and more serious to the indoor environment. The VOCs' concentration in indoor air after decoration is not very high, but due to the long stay in the room, the health risk of indoor personnel is greatly increased [4,5]. On the other hand, with the development of science and technology, the interior of the building is closed, the indoor artificial chemicals are increased, and the artificial environment enhances the influence of indoor pollutants on the human body.

In addition to the distribution of pollution sources [6], indoor environmental parameters (such as wind speed, temperature, humidity, etc.) also affect the distribution and harm of pollutants, and affect the human body's feelings and functions. Fang et al. [7] studies had shown that reducing temperature or relative humidity made the air quality more acceptable to people on the condition that indoor air pollutant concentration was certain. In other words, the satisfaction of air quality was directly related to the enthalpy of the air. The study by Yassin [8] et al. proposed a model for coupling statistical of wind speed distribution and diffusion of atmospheric pollutants. The results show that the turbulent wind has influence on the distribution of pollutants, and it can predict the distribution of pollutants in the free fluctuation. It can also analyze the effect of the mixed wind to the diffusion of pollutants.

Xia Ying [9] pointed out that the form of windows had little effect on the average volume coefficient of indoor air pollutants, but had a great influence on the distribution of indoor airflow, through studying on the effect of windows on the reduction of indoor air pollutants.

Affected by various environment factors, the diffusion volume of pollutants is related with the volume of interior space. The distribution of pollutants in the decoration of the house is not uniform, and the distribution form of pollutants in the specific residential also depends on the location of pollution sources. Under the diffusion intensity of the same sources, it is also affected by ventilating rate. When ventilating rate is large, residential interior decoration of benzene concentration is low. In addition, the release of benzene is also related with the indoor temperature and humidity in decorated houses [10].

On the base of analyzing synthetically the main factors affecting the concentration of volatile organic compounds (benzene) in the indoor environment, this text uses the related software to make numerical simulation, and study the mechanism of artificial guide flow of indoor environmental 
pollutants. It also analyzes the diffusion channel of indoor pollutants, by studying the change of airflow, temperature and relative humidity to reveal the rule of the distribution of pollutants which may provide reference and choice for the design model of indoor artificial environment.

\section{Material and methods}

The production of indoor pollutants and the properties of diluting diffusion are the emphasis of studying indoor air environment, which is the key point to how to reduce the indoor pollutant quickly and effectively. At present, the model of indoor pollution sources can be divided into physical model based on mass transfer theory and empirical model based on model experiment [11].

The empirical model is the reproduction of the experimental data, and the empirical formula can be used to predict the concentration distribution of other indoor pollutants in the same or similar conditions. Dunn et al. [12] proposed the first-order decay model.

In this paper, the turbulence model is used to simulate, and the size, location and pollutant emission of pollution sources are simplified. The construction of indoor air flow generally belongs to the turbulence incompressible and low-velocity. The literature [13] compares the simulation results of two different k- $\varepsilon$ turbulence models with natural convection, forced convection, mixed convection and jet flow. The results showed that the k- $\varepsilon$ turbulence model of RNG in the simulation of indoor air flow had a better comprehensive effect [14].

\section{Model building}

Because the boundary conditions of the space model can be determined qualitatively, it is decided that the computational domain of the model does not include the whole area of the building. In this paper, the computational domain of indoor space environment simulation is shown in Fig.1. The design space model is as follows:

(1) General office space as a model, the room size: $10 \mathrm{~m}^{*} 6 \mathrm{~m}^{*} 3 \mathrm{~m}$, the outer wall thickness of $0.30 \mathrm{~m}$, the inner wall thickness of $0.20 \mathrm{~m}$. The heat from the south window of the room is added to the South wall.

(2) The establishment of the coordinate system: as shown in Fig.1, the southwest corner of the room as the origin of o, length is $10 \mathrm{~m}$, width of $6 \mathrm{~m}$, height of $3 \mathrm{~m}$, the establishment of geometric model and mesh. In the room $X=0, Y=3, Z=1.5$ and $X=0, Y=7, Z=1.5$, respectively, set a size of $1.0 \mathrm{~m} \times 1.0 \mathrm{~m}$ outside the window.

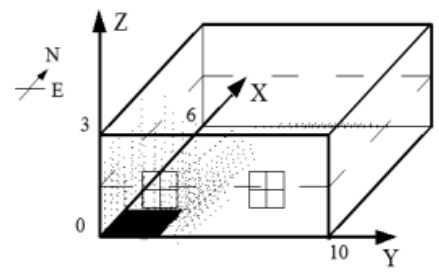

Fig.1 The model of numerical simulation

In order to obtain a unique solution of physical problems (various differential equations), various parameters of the boundary of the calculation domain are needed to set up $[15,16]$.

This simulation mainly studies the diffusion characteristics of indoor benzene concentration under the condition of natural ventilation [17]. Set the model room, the south wall south windows and east wall heat incoming, lighting heat out from the ceiling, the rest interior walls and doors are adiabatic, the southwest corner of the ground for benzene pollution gas concentrated source place has practical significance on the ground, used to simulate point source pollution.

The boundary conditions of each object in the room are shown in table 1 . 
Table1 Boundary conditions of various objects in the room

\begin{tabular}{lcl}
\hline Name & Boundary condition type & Numerical value \\
\hline East wall & Constant heat flux & Heat flow:375w \\
South wall & Constant heat flux & Heat flow: $1966 \mathrm{w}$ \\
West wall & Heat insulation & \\
North wall & Heat insulation & \\
Ceiling & Constant heat flux & Heat flow: $345 \mathrm{w}$ \\
Benzene & Steady flow & $7.2 \times 10^{-11} \mathrm{~kg} / \mathrm{m}^{3}$ \\
\hline
\end{tabular}

In fact, the air distribution in the room was affected by many factors. If all were taken into account, the model would be complicated and difficult to deal with, so it was necessary to make some reasonable simplifying assumptions, in this paper which are as follows

(1) The heat transfer of the wall and the internal heat source in the room is uniform;

(2) There is no radiation effect between the heat transfer surfaces in the room;

(3) Benzene gas is released from the upper surface of the floor.

\section{Results and analysis}

In order to analyze the concentration of indoor temperature, relative humidity, air velocity and pollutant, set the initial temperature of $20^{\circ} \mathrm{C}$, relative humidity $50 \%$, chose the plane of the room $1.5 \mathrm{~m}$ (breathing interval reference range) as the interface of the simulation results.

\section{The influence of air velocity, temperature and relative humidity on the distribution of benzene concentration}

Fig.2 5 showed the distribution of temperature, air velocity, relative humidity and benzene concentration on the horizontal section of $\mathrm{z}=1.5 \mathrm{~m}$.
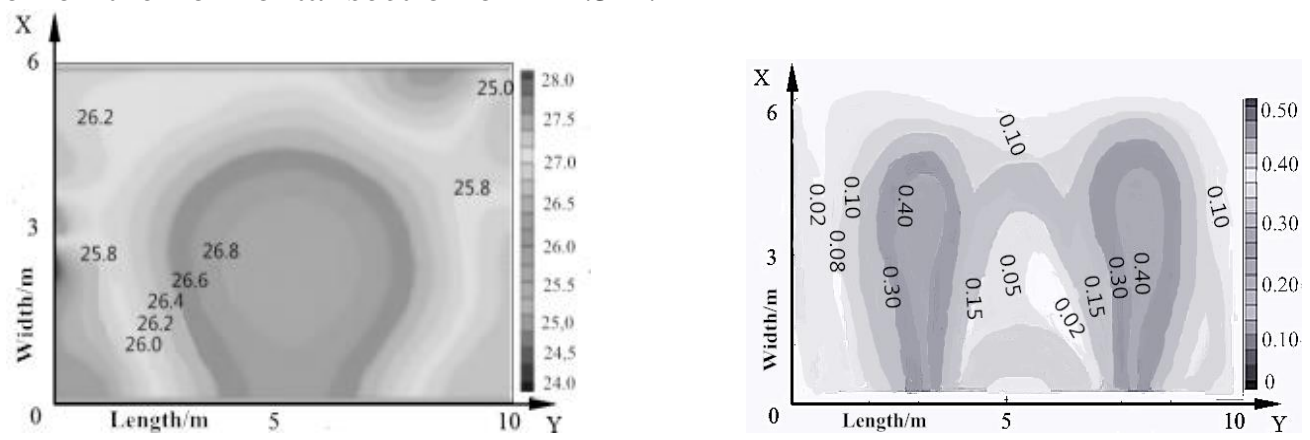

Fig. 2 Temperature distribution in section $\mathrm{z}=1.5 \mathrm{~m}$ Fig. 3 The velocity distribution of air flow in section $\mathrm{z}=1.5 \mathrm{~m}$
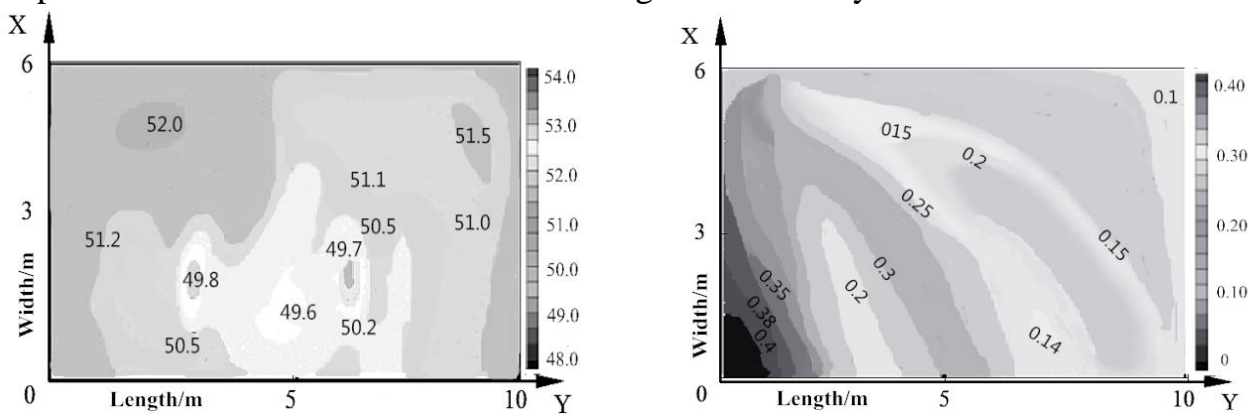

Fig.4 Relative humidity distribution in section Fig.5 Distribution of benzene concentration in section

It can be seen from Fig. 3 and Fig. 5 that the concentration of benzene is lower at the speed of airflow. The concentration of benzene in the vicinity of the pollution source is higher in Fig. 5, which is mainly affected by the pollution source.

This simulation experiment used the original room model to set the initial benzene concentration of $0.5 \mathrm{mg} / \mathrm{m}^{3}$, changing indoor temperature $\left(15^{\circ} \mathrm{C}, 20^{\circ} \mathrm{C}\right.$ and $\left.25^{\circ} \mathrm{C}\right)$ to analysis. Fig. 6 is the result of the change of benzene concentration in different indoor temperature. 

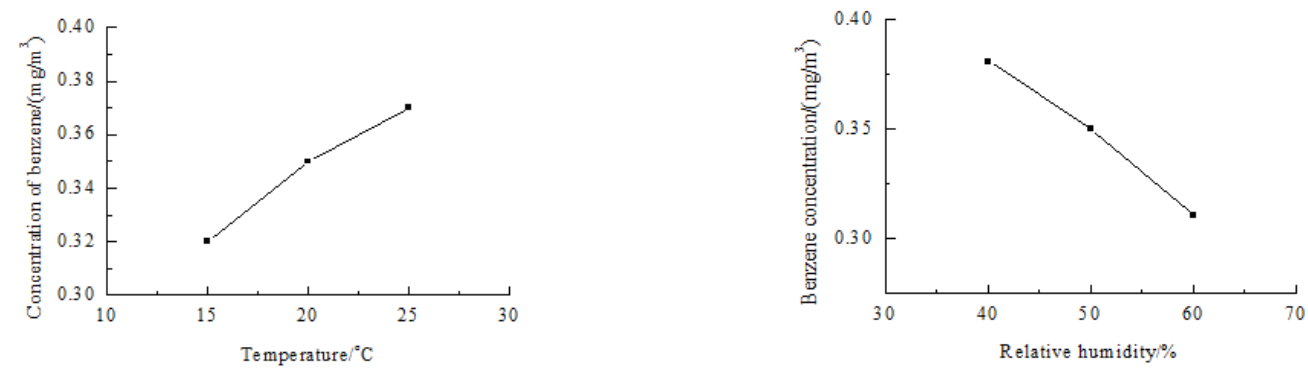

Fig.6 Concentration of benzene in different indoor temperature Fig.7 Concentration of benzene in different relative humidity

Keeping indoor relative humidity, indoor temperature of 15,20 and $25^{\circ} \mathrm{C}$, the average benzene concentration in the room was $0.32,0.35$ and $0.37 \mathrm{mg} / \mathrm{m}^{3}$. Figure 6 indicated that the higher the indoor temperature, the higher the concentration of benzene in the air. The higher the indoor temperature, the faster the spread of pollution sources benzene.

Based on the influence of air humidity on acceptable percentage of indoor air quality, the effect of air humidity on benzene pollution was further studied. With the original room model, set the initial benzene concentration of $0.5 \mathrm{mg} / \mathrm{m}^{3}$, set indoor relative humidity $(40 \%, 50 \%$, and $60 \%)$ for analysis. Fig. 7 Variation of benzene concentration under different relative humidity.

Keeping the indoor constant temperature, relative humidity in $40 \%, 50 \%$ and $60 \%$, the concentration of benzene decreased as the humidity increased, the average indoor benzene concentrations were $0.39,0.35$ and $0.31 \mathrm{mg} / \mathrm{m}^{3}$, and the relative initial concentration decreased by $22 \%, 30 \%$ and $38 \%$. In the indoor air, the relative humidity was higher under different relative humidity.

\section{Effects of temperature, relative humidity and air velocity on the concentration distribution of benzene}

In order to understand the change of each section on the effects of temperature, relative humidity and air velocity in the vertical direction and the benzene concentration in the range of $\mathrm{z}=1.3 \mathrm{~m} \sim 2.0 \mathrm{~m}$, section $0.1 \mathrm{~m}$, every one section is analyzed, and the parameters of each section of the simulated concentration, the mean value of each parameter of the simulation results were shown in table 2 . The variation trend of temperature, relative humidity, air velocity and benzene concentration on the vertical height were shown in Fig. 8 11.

Table 2 Simulation results of different parameters at different heights

\begin{tabular}{ccccccccc}
\hline Height $/ \mathrm{m}$ & $\mathrm{Z}=1.3$ & $\mathrm{Z}=1.4$ & $\mathrm{Z}=1.5$ & $\mathrm{Z}=1.6$ & $\mathrm{Z}=1.7$ & $\mathrm{Z}=1.8$ & $\mathrm{Z}=1.9$ & $\mathrm{Z}=2.0$ \\
\hline Temperature $/{ }^{\circ} \mathrm{C}$ & 26.5 & 26.6 & 26.7 & 26.7 & 26.9 & 27.0 & 27.1 & 27.2 \\
Relative humidity/\% & 50.4 & 50.3 & 50.1 & 49.7 & 49.3 & 48.9 & 48.4 & 48.2 \\
Airflow velocity $/(\mathrm{m} / \mathrm{s})$ & 0.13 & 0.127 & 0.126 & 0.126 & 0.121 & 0.119 & 0.111 & 0.110 \\
$\begin{array}{c}\text { Benzene concentration/ } \\
\left(\mathrm{mg} / \mathrm{m}^{3}\right)\end{array}$ & 0.176 & 0.180 & 0.182 & 0.186 & 0.190 & 0.193 & 0.195 & 0.197 \\
\hline
\end{tabular}
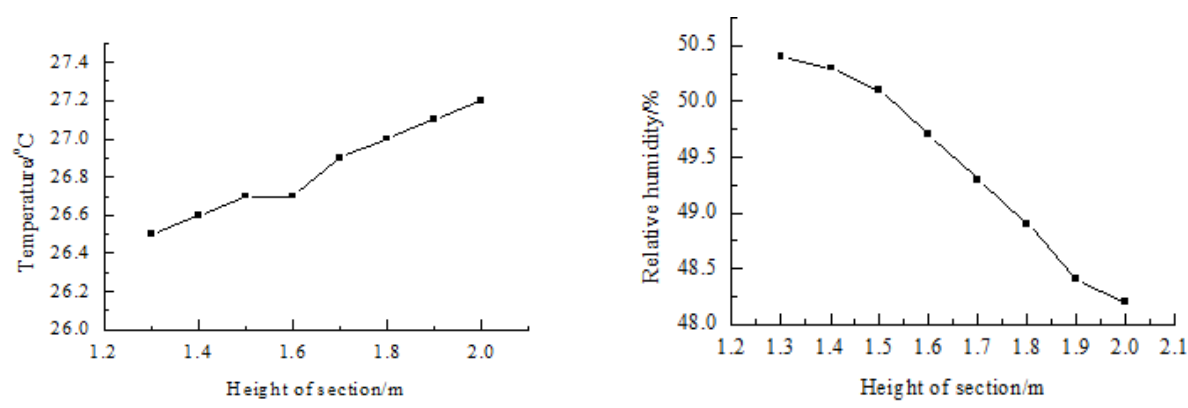

Fig. 8 The variety of temperature in the height direction Fig.9 The variety of relative humidity in the height direction 

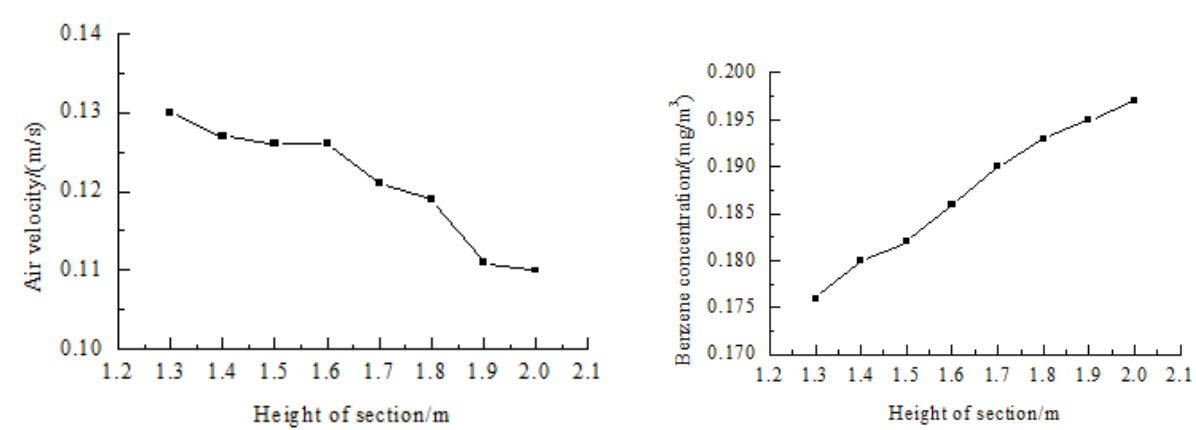

Fig.10 The variety of air velocity in the height direction Fig.11 The variety of benzene concentration in the height direction

Table 2 and figure 8 11shows that in the case of natural convection, the indoor temperature and the concentration of benzene increased with increasing height, relative humidity and air velocity decreases with the height increase, also in large section temperature, the concentration of benzene was higher, the gas flow velocity increasing section on the benzene concentration was lower. Therefore, the exhaust air can be effectively reduced in the section with high temperature.

\section{Conclusions}

On the section from the ground 1.5 meters in the room, the benzene concentration is lower in the cross section with high airflow velocity. The benzene concentration is higher in the higher temperature position. The concentration of pollutants is affected by temperature, humidity and wind speed besides the distribution of the source of pollution. The diffusion of benzene is faster in the room temperature. Under high relative humidity, the concentration of benzene was decreased obviously, and opening window for ventilation made the effect of the removal of benzene in the largest extent. Therefore, by increasing the room temperature and relative humidity while increasing the displacement ventilation, it could effectively remove the pollutants in the air of the room.

Based on simulated analysis, the results showed that the indoor temperature and the concentration of benzene would increase with the increase of the height of the section under the condition of natural ventilation. The variation trend of the relative humidity and air velocity was on the contrary. The benzene concentration was higher in the larger section of the temperature. The benzene concentration was lower in the section of the greater flow velocity. Therefore, setting the exhaust in the cross section position where the building temperature is high can effectively reduce the pollutant concentration

\section{References}

[1] Xiaolin Wang, Xiaoying Zhu. Occupational Health and Emergency Rescue, 24(1):13-15(2006)(In Chinese)

[2] Xiaoqin Xu, Wenjun Liu. Gansu science and Technology,30(7):49-52(2014).(In Chinese)

[3] Zhiqiang Ren,Qiong Chen,Zhulin Qian.Military Medical Journal of Southeast China,8(6):VII(2006).(In Chinese)

[4] Jinfu Hu. Science and Technology Innovation Herald, 2012(16): 44-48. (In Chinese)

[5] Yuguo sun. Northern Environmental,2012(5):234-236.(In Chinese)

[6] Wargocki P, Bako-biro Z,Clausen G.Energy and Buildings,2012,34(8):775-783.

[7] Fang L,Clausen G, Fanger P. Indoor Air,1998,8(4):276-284.

[8] Yassin M F. Environmental Monitoring and Assessment,2011 184 (6):3749-3760.

[9] Ying Xia.The study of the effect of windows on indoor air quality in residential building(Tianjin university press,2006).(In Chinese)

[10] Yuhong Luo, Xiaorong Zhao, Safety and Environmental Engineering, 15(2): 54-56(2008). (In Chinese) 
[11] Yuangao Wen. Research on the correlation between outdoor and indoor air pollutants.(Shanghai Jiao Tong University Press,2008).(In Chinese)

[12]Dunn J E.Atmospheric Environment, 1987,21(2):425-430.

[13]Zhao Zhang, Wei Zhang, Zhiqiang John Zhai, et al. HVAC\&R Research, 13(6):871-886(2007).

[14] Shih T H, Liou W W, Shabbir A, et al.Computers and Fluids,24(3):227-238(1995).

[15] Wenquan Tao, Numerical Heat Transfer(Xi'an Jiaotong University Press,2001).(In Chinese)

[16] Huang H Y, Haghighat F. Building and Environment,38(8):995-1005(2003).

[17]Haofu Shi, Hongwei Tan, Liang Ji, et al.Building Energy and Environment, 31(1):57-60(2012).(In Chinese) 